\title{
The Art of Surgery
}

\author{
Anuj Shah MD, Anne Nugent MPH
}

The processes of performing an operation and of creating woodcut prints are surprisingly similar. Both require extensive preparation prior to beginning and adaptability in their execution. As in surgery, the artist assembles his instruments: gouges, chisels, and a block of wood with a grain that best accommodates the artist's design. Drawing and carving an image in reverse allows for the proper orientation once printed. The artist removes portions of the wood block with his tools, leaving the raised uncut surfaces to transfer the ink and print the image. The texture of the wood grain and how the wood interacts with each chisel stroke is imparted onto the final print. Much like a surgeon during an operation, the artist makes adjustments and
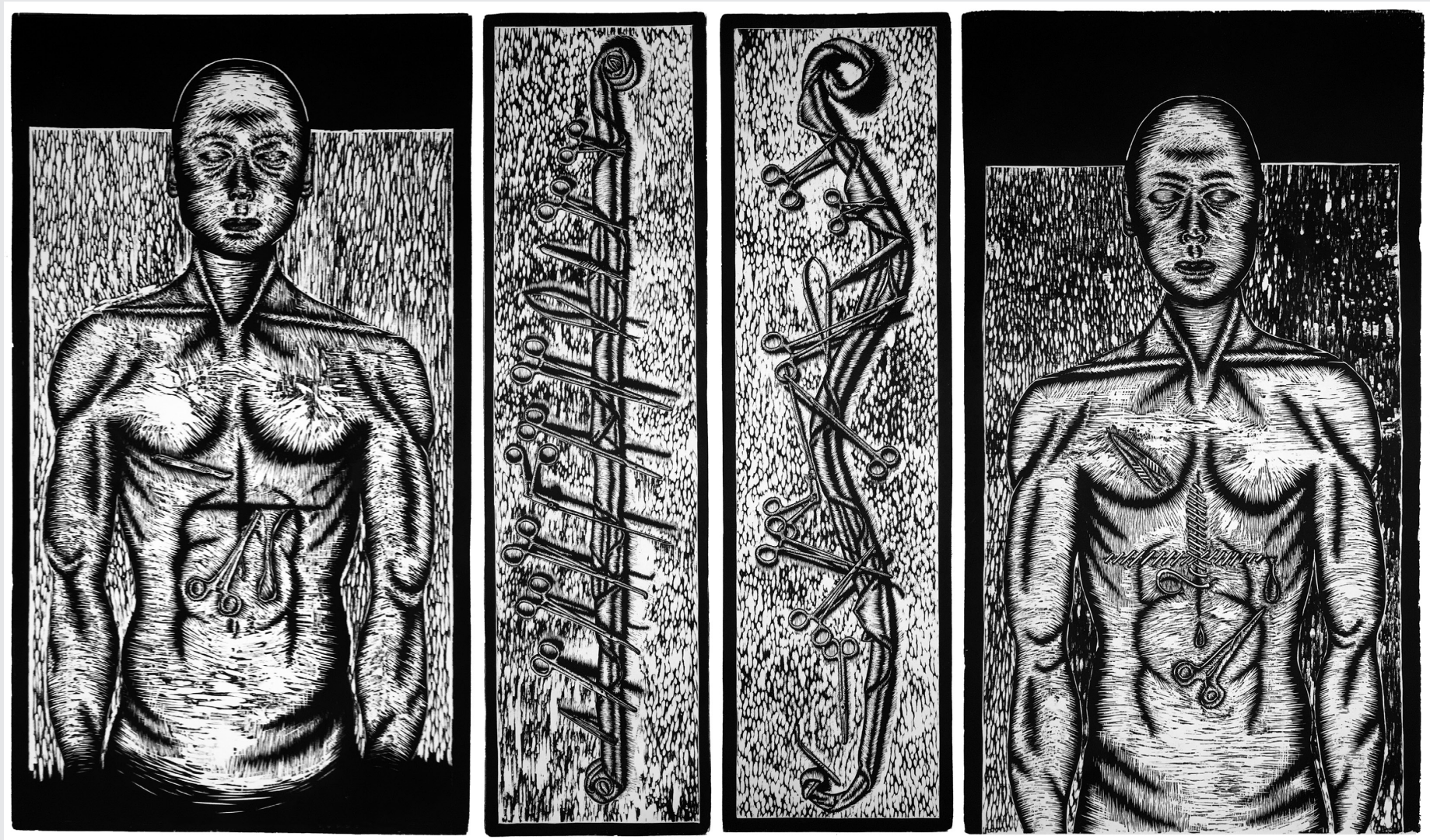

From Left to Right: Opening, Beginning, End, Closing.

Corresponding author: Anuj Shah

Contact Information: Artanuj@gmail.com

DOI: 10.12746/swrccc.v7i27.523 



Upper Left: Cutting, Upper Right: Dissecting, Lower Left: Sewing, Lower Right: Tying. 
modifications while staying true to the original intent of the piece.

Operating room personnel carefully prepare a patient for surgery, often drawing incision sites on the skin and orienting the patient precisely. Similar to surgical prep, printing the image of a woodcut also requires careful planning. To prepare the printing press, the artist adjusts the roller height to ensure proper pressure without stressing the wood block. A registration template marks where the block should go in the press to ensure correct margins and orientation. After mixing the ink to the proper consistency, the artist rolls the ink onto the woodcut with a rubber brayer. The amount of pressure used when rolling on the ink is crucial. Too much pressure can cause the plate to be too dark and backgrounds will bleed into the image; too little pressure can cause the image to appear faded and incomplete. Finally, the paper is soaked in water to allow absorption of the ink, pressed onto the wood block, and hung to dry. An artist controls the pressure of his carving tools and printing press as a surgeon controls the pressure of the scalpel and other surgical instruments.

"The Art of Surgery" is a series of woodcut prints that depicts the surgical procedure from start to finish. The prints convey not only an understanding of the surgical field, but also the emotions of the surgeon/artist. The first print, "Opening," concerns the apprehension felt when starting a procedure. "Closing" mirrors the first print and depicts the relief of completing a procedure. The similarities between the two leave the viewer somewhat unsatisfied, since the intricacies of the procedure are hidden behind the closing suture. The four smaller prints, titled simply "Cutting," "Dissecting," "Sewing," and "Tying," are intentionally chaotic and hard to interpret, as often is the case during surgery. Buttressing the smaller prints are "Beginning" and "End," which reflect the surgeon's often futile attempt to maintain order during the procedure by precisely lining up all the instruments. The repetitive nature of woodcut prints is what gives it beauty and elegance. As a surgeon learns from each case, an artist learns from each prior print, as subtle variations occur. Prints in "The Art of Surgery" series represent growth from the first print to the last.

Woodcut artist H.A.P. Grieshaber maintains, "The woodcutter with his knife is like a farmer with his plow, like a gardener with his spade, like a butcher with his cleaver, protected in his actions by the law of his métier." Dr. Shah elevates the comparison in the artistry of surgery through his elegant woodcuts, and would agree with Fritz Eichenberg, "To handle a beautiful piece of wood is sheer delight, to cut into its surface a never-ending adventure, to search for its hidden qualities always exciting."1

Keywords: woodcut prints, surgery

Anuj Shah, MD FACS, is an associate professor of surgery at the University of Missouri-Kansas City School of Medicine and the director of the Comprehensive Hernia Center at Truman Medical Center in Kansas City, MO. Dr. Shah is also an accomplished artist, specializing in woodcut prints. It has taken him nearly ten years to complete this series of prints, during which time he has "grown professionally and personally, both as an artist and a surgeon."

Submitted: $1 / 5 / 2019$
Conflicts of interest: none

This work is licensed under a Creative Commons Attribution-ShareAlike 4.0 International License.

\section{REFERENCE}

1. Eichenberg, Fritz. The Art of the Print: Masterpieces, History, Techniques. New York: Harry B. Abrams, Inc., 1976. 